\title{
Event detection using population-based health care databases in randomized clinical trials: a novel research tool in interventional cardiology
}

This article was published in the following Dove Press journal:

Clinical Epidemiology

18 September 2013

Number of times this article has been viewed

\author{
Leif Thuesen' \\ Lisette Okkels Jensen ${ }^{2}$ \\ Hans Henrik Tilsted ${ }^{3}$ \\ Michael Mæng' \\ Christian Terkelsen' \\ Per Thayssen ${ }^{2}$ \\ Jan Ravkilde 3 \\ Evald Høj Christiansen' \\ Hans Erik Bøtker' \\ Morten Madsen ${ }^{4}$ \\ Jens F Lassen' \\ 'Department of Cardiology, Aarhus \\ University Hospital, Skejby, Denmark; \\ ${ }^{2}$ Department of Cardiology, Odense \\ University Hospital, Odense, Denmark; \\ ${ }^{3}$ Department of Cardiology, Aalborg \\ University Hospital, Aalborg, \\ Denmark; ${ }^{4}$ Department of Clinical \\ Epidemiology, Aarhus University \\ Hospital, Skejby, Denmark
}

Correspondence: Leif Thuesen

Department of Cardiology,

Aarhus University Hospital,

Skejby, Denmark

$\mathrm{Tel}+4578452112$

Fax +45 78452112

Email leif.thuesen@ki.au.dk
Aim: To describe a new research tool, designed to reflect routine clinical practice and relying on population-based health care databases to detect clinical events in randomized clinical trials.

Background: Randomized clinical trials often focus on short-term efficacy and safety in a controlled environment. Trial follow-up may be linked with study-related investigations and differ from routine clinical practice. Because treatment and control in randomized trials differ from daily practice, trial results may have reduced general applicability and may be of limited value in clinical decision-making. Further, it is economically very costly to conduct randomized clinical trials.

Methods and results: Population-based health care databases collect data continuously and prospectively, and make it possible to monitor lifelong outcomes of cardiac interventions in large numbers of patients. This strengthens external validity by eliminating the effects of studyrelated monitoring or diagnostic tests. Further, follow-up data can be obtained at low expense. Importantly, data sources encompassing a complete population are likely to reflect clinical practice. Because population-based health care databases collect data for quality-control and administrative purposes unrelated to scientific investigations, certain biases, such as nonresponse bias, recall bias, and bias from losses to follow-up, can be avoided.

Conclusion: Event detection using population-based health care databases is a new research tool in interventional cardiology that may allow large, low-cost, randomized clinical trials to reflect daily clinical practice, covering a broad range of patients and end points with complete lifelong follow-up.

Keywords: clinical study, national registries, event detection, PCI, coronary stents

\section{Introduction}

In medicine, the randomized controlled clinical trial (RCT) is the gold standard in research design for assessing the level of evidence for new treatments. ${ }^{1}$ Nevertheless, the clinical applicability of RCT results has shortcomings. RCTs often focus on shortterm efficacy and safety in a controlled clinical environment among well-educated affluent patients. ${ }^{2}$ In addition, the scientific investigation per se may influence the subject and the results of an investigation, also called the Hawthorne effect. ${ }^{3}$ Important elements of study design are intensity of and methods for collection of follow-up data. These elements are likely to influence the completeness, validity, and number of events assessed, and may lead to biased estimates of the prognosis, because some study participants drop out over time.

In a population-based health care database, data are collected for quality-control or administrative purposes. This may reduce certain forms of bias, such as nonresponse 
bias, recall bias, and bias from loss to follow-up, which may influence prognostic estimates. ${ }^{4}$ Also, there are considerable costs associated with conducting an RCT.

Based on our experience with head-to-head stent comparisons, ${ }^{5-8}$ we present a novel research tool in interventional cardiology: event detection using population-based health care databases. When event detection relies on populationbased databases, conduct of RCTs does not influence everyday clinical practice. Complete and lifelong follow-up is possible, and a large-scale RCT may be performed at relatively low cost.

\section{Population-based databases}

Event detection using population-based databases requires access to existing health care databases, permission to merge different databases at the patient level, and algorithms to ensure anonymity for individual patients. It is essential that the database cover the target population over the entire study period and that patient migration out of the catchment area is minimal. ${ }^{9}$

\section{Clinical end points in coronary stent trials}

Treatment with coronary stents is usually assessed using safety end points (all-cause death, cardiac death, and myocardial infarction [MI]) and efficacy end points (targetlesion or vessel revascularization [TLR or TVR] following percutaneous coronary intervention $[\mathrm{PCI}]$ or coronary bypass surgery). ${ }^{10}$ It is well known that study-related follow-up procedures may affect the number of end points detected. In interventional cardiology, the Benestent study ${ }^{11}$ noted that TVR was found more often in patients undergoing systematic angiographic follow-up than in patients followed clinically. Thus, mandated angiographic monitoring increases event rates significantly, as the presence of visually assessed coronary artery stenosis leads to new revascularization procedures. Much effort has been made to avoid studyinduced repeat revascularizations. In the Nordic Bifurcation studies, ${ }^{12}$ clinical and angiographic monitoring were separated in time, with clinical follow-up preceding angiographic control. Other investigators have established strict rules for revascularization following angiographic detection of a new coronary artery narrowing. ${ }^{13}$

Clinical study-related monitoring by means of outpatient visits or telephone contacts also is likely to lead to changes in patient compliance, increased detection of events, and registration of events that would remain undetected in everyday clinical practice.

\section{Event detection using population databases in the Sort Out trials}

The Sort Out II-V trials $\mathrm{s}^{5-8}$ used existing national registries covering the entire population to detect events in the study cohorts. Thus, participants were exposed to the same clinical monitoring as nonstudy patients. Data on mortality (cardiac and noncardiac) were obtained from the Danish Civil Registration System and the National Registry of Causes of Death, ${ }^{14,15}$ hospital admission for myocardial infarction from the Danish National Registry of Patients, ${ }^{16}$ and basic descriptive data, coronary angiography, repeat PCI, and coronary bypass surgery from the Western Denmark Heart Registry. ${ }^{17}$ An important advantage of this study approach is the ability to describe baseline demographics and clinical outcomes in all patients treated with coronary stents during the study period, and not only those included in the RCT. Thus, important information is available regarding the general applicability, ie, the external validity, of study results.

In Denmark, all citizens have a personal civil registration number assigned at birth or upon immigration. ${ }^{14}$ This unique personal identifier allows linkage of individual-level information across registries and databases. The Danish Civil Registration System is updated daily, and maintains records on date of birth, death, and current residence of all Danish citizens. The Danish National Registry of Patients contains information on all admissions and outpatient visits to the 52 Danish hospitals. For each hospital admission, the registry records dates of admission and discharge, surgical procedures performed, and up to 20 diagnoses classified according to the International Classification of Diseases (ICD), eighth revision, until the end of 1993, and tenth revision thereafter. ${ }^{16}$ The Western Denmark Heart Registry contains detailed patient- and procedure-specific information on all coronary angiographies, coronary interventions and coronary bypass surgery performed at the three interventional and eight noninterventional cardiac centers in Western Denmark. ${ }^{17}$ Information from the Western Denmark Heart Registry and the Danish National Registry of Patients has been validated in earlier studies, and the registries' data completeness and validity are continuously monitored. ${ }^{16,18}$ The Sort Out trials ${ }^{5-8}$ used the Danish Civil Registration System to assess all-cause mortality. The original death certificates were obtained from the National Registry of Causes of Death to classify deaths by underlying cause.

We defined new MIs as rehospitalization for MI after the index PCI, based on MI-related admissions and readmissions I (ICD-10 codes I21-I21.9) identified from the Danish National Patient Registry. Information on new diagnostic 
angiograms and new revascularizations performed with coronary bypass surgery or PCI was available from the Western Denmark Heart Registry. All possible end points were adjudicated by an independent end-point committee consisting of interventional and noninterventional cardiologists, who examined hospital files and reviewed diagnostic and therapeutic angiograms. The trial end points were allcause death, cardiac death, noncardiac death, MI, TVR, TLR, and stent thrombosis, using Academic Research Consortium definitions. ${ }^{10}$ The health care database-based event detection is shown schematically in Figure 1.

\section{Randomization linked to a health care database}

In the ongoing Swedish TASTE trial, ${ }^{19,20}$ the investigators have added a randomization module to their population-based PCI database, taking the integration of clinical databases and RCTs to a higher level. In TASTE, patients admitted with acute ST-elevation MI for primary PCI are randomized to thrombectomy or to conventional primary PCI. When initial procedural data are entered in the database and prespecified inclusion and exclusion criteria are fulfilled, the operator will have to consider randomization. This is an excellent example of a study design incorporating the essentials of an RCT in interventional cardiology. The study has a large sample size ( $>5,000$ patients), a high inclusion rate, and a focused primary end point (1-month all-cause mortality). ${ }^{19}$ Combining event detection using population-based health care databases with a randomization module may be a very efficient and cost-effective option when designing large scale RCTs with long term follow-up.

\section{Discussion}

Event detection using population-based registries in RCTs is a novel research tool that may be applied in a number of clinical settings, including coronary interventions. ${ }^{21}$ This approach allows large RCTs to reflect daily clinical practice, to cover a broad range of patients, and to facilitate complete lifelong follow-up at low cost.

Drug-eluting stents were accepted for extensive clinical use based on randomized trials involving relatively few and selected patients, with angiographic follow-up data serving as the primary end point. ${ }^{22-24}$ Years later, detection of an increased risk of late stent thrombosis in patients treated with these stents raised questions about the scientific rigor of the device-approval process. Subsequently, large RCTs with few exclusion criteria and clinical end points were recommended to document acceptable safety and efficacy of new stents. Event detection using population-based databases may provide additional clinical support for this type of study.

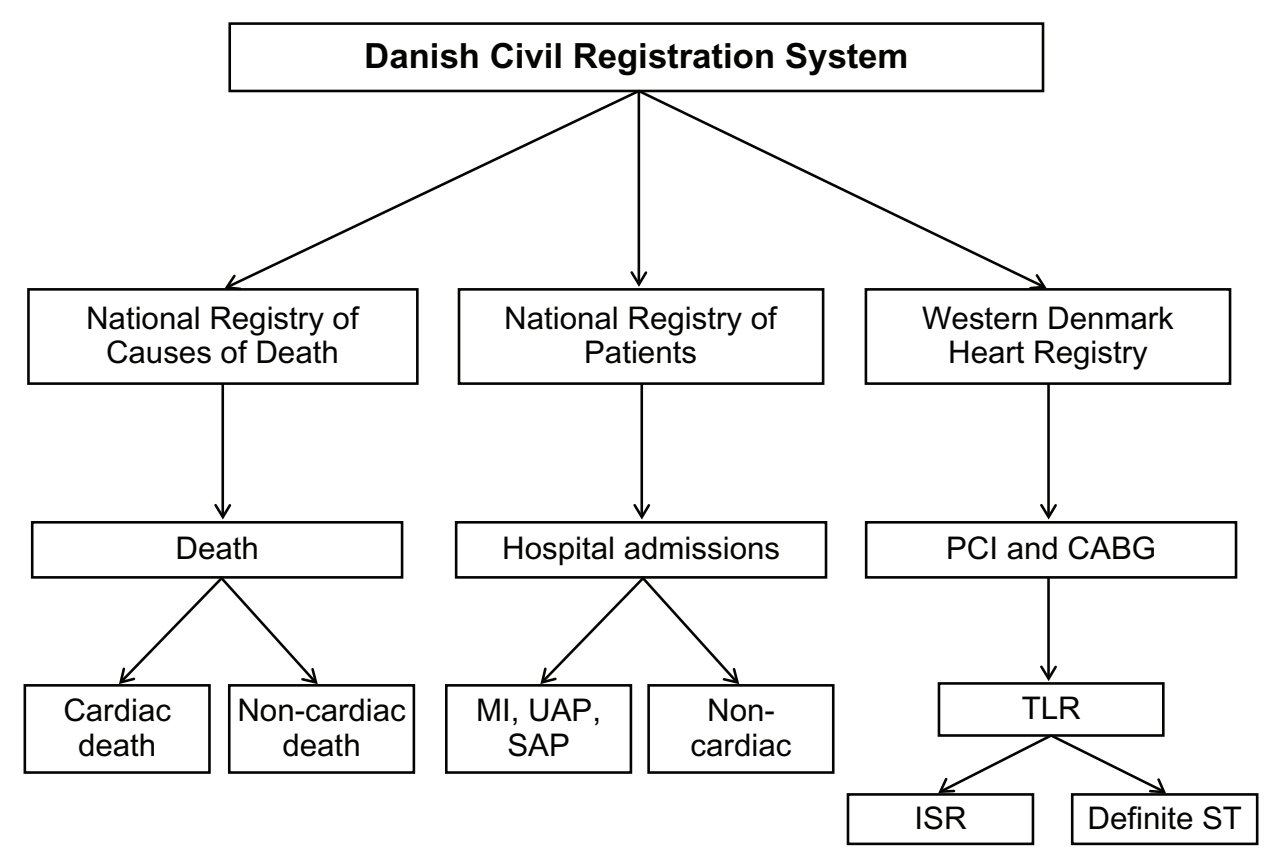

Figure I Event detection using population-based health care databases. The Danish Civil Registration System allows linkage of individual-level information across registries. ${ }^{14}$ It is updated daily, and maintains records on date of birth, death, and current residence of all Danish citizens. The National Registry of Causes of Death provides information on causes of death. ${ }^{15}$ The National Registry of Patients contains information on all admissions and outpatient visits. ${ }^{16}$ The Western Denmark Heart Registry provides detailed patientand procedure-specific information on all coronary angiographies, coronary interventions, and coronary bypass surgery procedures performed in Western Denmark. ${ }^{17}$ Abbreviations: PCl, percutaneous coronary intervention; CABG, coronary artery bypass grafting; MI, myocardial infarction; UAP, unstable angina pectoris; SAP, stable angina pectoris; TLR, target-lesion revascularization; ISR, in-stent restenosis; ST, stent thrombosis. 
This method may make it possible, at low cost, to use an RCT design to study the safety and efficacy of medical devices in large cohorts of unselected patients, with a lifelong follow-up period and a clinical research setting identical to routine clinical practice.

Furthermore, combining different health care databases may allow assessment of variables not directly related to the RCT for generation of hypotheses for new prospective studies. ${ }^{25,26}$ Finally, combining event detection using population-based health care databases and a randomization module within the database ${ }^{20}$ may be a very efficient and cost-effective option for large-scale long-term follow-up RCTs.

We do not know the extent to which event rates differ between clinical studies using population database-based event detection and those using conventional angiographic or other follow-up for event detection. It is likely that registration of death will be the same. With symptom-driven event detection, incidence of spontaneous MI may be slightly reduced and procedure-related MI further reduced due to fewer revascularizations. Because new revascularizations will be symptom-driven, it also is likely that rates of new revascularizations will be lower. However, the randomization process would balance possible under- or overreporting in the study groups.

The generalizability, or external validity, of study findings is a common challenge in clinical research, since information about nonstudy patients remains unknown or associated with a high degree of uncertainty. In this context, trials using population-based health care databases for event detection provide a significant advantage. ${ }^{25,26}$ Since all patients are registered in the existing databases, equally valid procedure and background information is available for both study patients and nonstudy patients.

\section{Limitations}

Databases have important limitations, which are frequently ignored, because researchers do not control methods of data collection. Therefore, a primary concern in health care database-based event detection is related to the quality of health care databases used. Here, a prerequisite is reliable population-based databases, which register all relevant data in a timely manner in a well-defined population. Additional requirements include the ability to identify all patients and link their data among different databases. Further, it is important to review and validate the information recorded in the databases continuously. ${ }^{25}$
So far, our population-based health care database event detection has not been evaluated or approved by competent national health authorities. Further, we have no comparison of traditional event detection using clinical follow-up by phone call or outpatient visits and data registration by clinical research forms versus our proposed health care databasebased event detection. Therefore, we may suggest a randomized comparison of the different forms of event detection to describe possible event-rate differences and a comparison of event rates and types of events detected by traditional event detection versus a health care database-based event detection in the same study cohort.

\section{Ethical considerations}

There are specific ethical aspects to using population-based health care database event detection in RCTs. First, the randomized patient should be informed how follow-up data will be obtained, and that, in principle, the event detection will be lifelong. Second, randomized and nonrandomized patients should be informed that treatment and outcome data will be registered in national health care databases and used to describe general treatment results and to assess the external validity of ongoing RCTs.

\section{Conclusion}

Event detection using population-based health care databases is a new research tool in interventional cardiology that may allow large RCTs to reflect daily clinical practice, to cover a broad range of patients, and to facilitate complete lifelong follow-up at low cost.

\section{Disclosure}

The authors report no conflicts of interest in this work.

\section{References}

1. Silber S, Albertsson P, Avilés FF, et al. Guidelines for percutaneous coronary interventions. The Task Force for Percutaneous Coronary Interventions of the European Society of Cardiology. Eur Heart J. 2005;26(8):804-847.

2. Schneeweiss S, Avorn J. A review of uses of health care utilization databases for epidemiologic research on therapeutics. J Clin Epidemiol. 2005;58(4):323-337.

3. Fletcher RH, Fletcher SW. Treatment. In: Clinical Epidemiology: The Essentials. Baltimore: Lippincott \& Wilkins; 2005:125-145.

4. Sorensen HT, Lash TL, Rothman KJ. Beyond randomized controlled trials: a critical comparison of trials with nonrandomized studies. Hepatology. 2006;44(5):1075-1082.

5. Christiansen EH, Jensen LO, Thayssen P, et al. Biolimus-eluting biodegradable polymer-coated stent versus durable polymer-coated sirolimus-eluting stent in unselected patients receiving percutaneous coronary intervention (SORT OUT V): a randomised non-inferiority trial. Lancet. 2013;381(9867):661-669. 
6. Jensen LO, Thayssen P, Hansen HS, et al. Randomized comparison of everolimus-eluting and sirolimus-eluting stents in patients treated with percutaneous coronary intervention: the Scandinavian Organization for Randomized Trials with Clinical Outcome IV (SORT OUT IV). Circulation. 2012;125(10):1246-1255.

7. Rasmussen K, Maeng M, Kaltoft A, et al. Efficacy and safety of zotarolimus-eluting and sirolimus-eluting coronary stents in routine clinical care (SORT OUT III): a randomised controlled superiority trial. Lancet. 2010;375(9720):1090-1099.

8. Galloe AM, Thuesen L, Kelbaek H, et al. Comparison of paclitaxel- and sirolimus-eluting stents in everyday clinical practice: the SORT OUT II randomized trial. JAMA. 2008;299(4):409-416.

9. Furu K, Wettermark B, Andersen M, Martikainen JE, Almarsdottir AB, Sørensen HT. The Nordic countries as a cohort for pharmacoepidemiological research. Basic Clin Pharmacol Toxicol. 2010;106(2):86-94.

10. Cutlip DE, Windecker S, Mehran R, et al. Clinical end points in coronary stent trials: a case for standardized definitions. Circulation. 2007;115(17):2344-2351.

11. Ruygrok PN, Melkert R, Morel MA, et al. Does angiography six months after coronary intervention influence management and outcome? Benestent II Investigators. J Am Coll Cardiol. 1999;34(5):1507-1511.

12. Steigen TK, Maeng M, Wiseth R, et al. Randomized study on simple versus complex stenting of coronary artery bifurcation lesions: the Nordic bifurcation study. Circulation. 2006;114(18):1955-1961.

13. Kelbaek H, Thuesen L, Helqvist S, et al. The stenting coronary arteries in non-stress/benestent disease (SCANDSTENT) trial. J Am Coll Cardiol. 2006;47(2):449-455.

14. Frank L. Epidemiology. When an entire country is a cohort. Science. 2000;287(5462):2398-2399.

15. Juel K, Helweg-Larsen K. The Danish registers of causes of death. Dan Med Bull. 1999;46(4):354-357.

16. Andersen TF, Madsen M, Jørgensen J, Mellemkjoer L, Olsen JH. The Danish National Hospital Register. A valuable source of data for modern health sciences. Dan Med Bull. 1999;46(3):263-268.
17. Jensen LO, Maeng M, Kaltoft A, et al. Stent thrombosis, myocardial infarction, and death after drug-eluting and bare-metal stent coronary interventions. J Am Coll Cardiol. 2007;50(5):463-470.

18. Madsen M, Davidsen M, Rasmussen S, Abildstrom SZ, Osler M. The validity of the diagnosis of acute myocardial infarction in routine statistics: a comparison of mortality and hospital discharge data with the Danish MONICA registry. J Clin Epidemiol. 2003;56(2):124-130.

19. Frobert O, Lagerqvist B, Gudnason T, et al. Thrombus aspiration in STelevation myocardial infarction in Scandinavia (TASTE trial). A multicenter, prospective, randomized, controlled clinical registry trial based on the Swedish angiography and angioplasty registry (SCAAR) platform. Study design and rationale. Am Heart J. 2010;160(6):1042-1048.

20. James S, Frobert O, Lagerqvist B. Cardiovascular registries: a novel platform for randomised clinical trials. Heart. 2012;98(18): 1329-1331.

21. Kastrati A. SORT OUT V: A new episode in the DES wars. Lancet. 2013;381(9867):609-611.

22. Morice MC, Serruys PW, Sousa JE, et al. A randomized comparison of a sirolimus-eluting stent with a standard stent for coronary revascularization. $N$ Engl J Med. 2002;346(23):1773-1780.

23. Moses JW, Leon MB, Popma JJ, et al. Sirolimus-eluting stents versus standard stents in patients with stenosis in a native coronary artery. N Engl J Med. 2003;349(14):1315-1323.

24. Stone GW, Ellis SG, Cox DA, et al. A polymer-based, paclitaxeleluting stent in patients with coronary artery disease. $N$ Engl J Med. 2004;350(3):221-231.

25. Sørensen HT, Baron JA. Registries and medical databases. In: Olsen J, Saracci R, Trichopoulos D, editors. Teaching Epidemiology: A Guide for Teachers in Epidemiology, Public Health and Clinical Medicine. Oxford: Oxford University Press; 2009.

26. Sajadieh A, Storm HH, Hansen JF. Verapamil and risk of cancer in patients with coronary artery disease. DAVIT Study Group. Danish Verapamil Infarction Trial. Am J Cardiol. 1999;83(9):1419-1422, A9.
Clinical Epidemiology

\section{Publish your work in this journal}

Clinical Epidemiology is an international, peer-reviewed, open access journal focusing on disease and drug epidemiology, identification of risk factors and screening procedures to develop optimal preventative initiatives and programs. Specific topics include: diagnosis, prognosis, treatment, screening, prevention, risk factor modification, systematic

\section{Dovepress}

reviews, risk \& safety of medical interventions, epidemiology \& biostatical methods, evaluation of guidelines, translational medicine, health policies \& economic evaluations. The manuscript management system is completely online and includes a very quick and fair peer-review system, which is all easy to use. 